\title{
Study on the High Temperature Friction and Wear Behaviors of Cu-Based Friction Pairs in Wet Clutches by Pin-on-Disc Tests
}

\author{
Er-Hui Zhao, ${ }^{1}$ Biao $\mathrm{Ma},{ }^{1,2}$ and He-Yan $\mathrm{Li}^{1,2}$ \\ ${ }^{1}$ School of Mechanical Engineering, Beijing Institute of Technology, Beijing, China \\ ${ }^{2}$ Collaborative Innovation Center of Electric Vehicles in Beijing, Beijing, China \\ Correspondence should be addressed to He-Yan Li; lovheyan@bit.edu.cn
}

Received 10 January 2017; Revised 2 May 2017; Accepted 8 May 2017; Published 29 May 2017

Academic Editor: Carlos Navarro

Copyright (c) 2017 Er-Hui Zhao et al. This is an open access article distributed under the Creative Commons Attribution License, which permits unrestricted use, distribution, and reproduction in any medium, provided the original work is properly cited.

\begin{abstract}
This work is devoted to the study of the high temperature friction and wear behaviors of Cu-based friction pairs in wet clutches under different temperatures, rotation speeds, and loads. Pin-on-disc tests are carried out on the UMT-3. The friction coefficient, wear factor, and high temperature wear mechanism are primarily analyzed. The results show that as the temperature rises from $120^{\circ} \mathrm{C}$ to $420^{\circ} \mathrm{C}$, the friction coefficient increases from 0.28 to 0.35 at first and then decreases to 0.30 , when the vibration of friction coefficient is significantly identified. Meanwhile, the wear factor grows gradually from $K=7.9 \times 10^{-8} \mathrm{~g} / \mathrm{Nm}$ to $K=41.8 \times 10^{-8} \mathrm{~g} / \mathrm{Nm}$ at first and then grows sharply to $K=112.2 \times 10^{-8} \mathrm{~g} / \mathrm{Nm}$. The main wear mechanisms are abrasive wear and ploughing wear when the temperature is below $345^{\circ} \mathrm{C}$, and the wear seriously deteriorates when the temperature exceeds $345^{\circ} \mathrm{C}$, when the wear mechanism changes to adhesive wear and delamination wear.
\end{abstract}

\section{Introduction}

$\mathrm{Cu}$-based powder metallurgy friction pairs are widely used in the wet multidisc clutch, which is one of the main parts in tracked-vehicle integrated transmissions. As power switching and torque transfer devices, wet clutches often work under extremely atrocious conditions, such as high initial sliding velocity, rapid temperature rise, and high surface pressure. The failures of wet clutches due to the friction and wear problems have become a limiting factor for the use of integrated transmissions. Therefore, the friction and wear behaviors of $\mathrm{Cu}$-based friction pairs in wet clutches have to be thoroughly investigated.

The friction and wear behaviors of $\mathrm{Cu}$-based friction pairs in wet clutches crucially depend on the operating conditions. However, the operating conditions in wet clutches are complex and unstable. Gao et al. [1], Deur et al. [2], Ompusunggu et al. [3], and Iqbal et al. [4] proposed numerical models and tests to investigate the engagement of wet clutches. At the initial stage of engagement, friction plates are separated from the mating discs and rotate with a high relative speed. Then, asperity contacts emerge and the relative speed decreases sharply. During the engagement of wet clutches, a large quantity of heat is generated intensively in 1 second, and the temperature rises rapidly at the interfaces of friction pairs. Researchers, such as Mansouri et al. [5], Jen and Nemecek [6], Ingram et al. [7], Seo et al. [8], and Wenbin et al. [9], investigated the heat transfer, temperature distribution, and thermal stresses of wet clutches by numerical models and experiments. The temperature distribution at the contact surfaces and the thermal stresses in the friction pairs are nonhomogeneous. The friction pairs can buckle due to the elevated temperatures and thermal stresses that occur during clutch engagements. Therefore, the friction and wear behaviors of $\mathrm{Cu}$-based friction pairs will be influenced by the deterioration of operating conditions.

The friction and wear behaviors of wet clutches have long been investigated by numerical and experimental methods. Xiong et al. [10] investigated the effects of $\mathrm{Fe}$ and $\mathrm{SiO}_{2}$ friction components on the friction and wear behaviors of the $\mathrm{Cu}$ based friction materials by an experimental method, and the wear mechanisms were analyzed. Ost et al. [11] investigated the friction and wear behaviors of paper-based wet clutch friction pairs by both SAE\#II and pin-on-disc tests, and the 


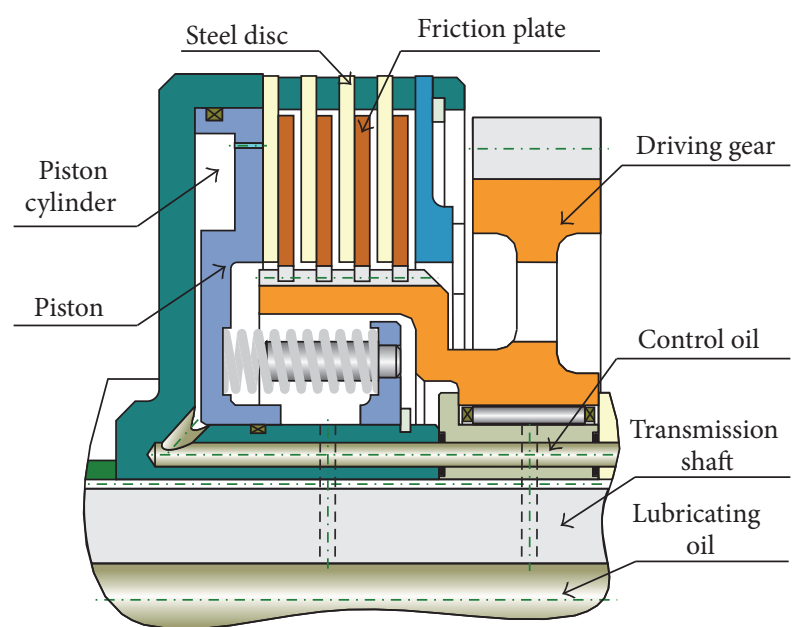

FIGURE 1: Structure diagram of wet multidisc clutch.

influences of material parameters and operating conditions on friction coefficient and wear rate were analyzed. Nyman et al. [12] investigated the influence of changes in the topography of the sintered friction material on the friction characteristics of wet clutches by an experimental method. Yao et al. [13] investigated the characteristics of a worn surface of $\mathrm{Cu}$-based powder metallurgy brake materials after working under service condition, and the main mechanisms were discussed. Zhou et al. [14] investigated the drag torque in a two-speed dual clutch transmission by numerical and experimental methods. Li et al. [15] presented a methodology for prediction of wear in the friction lining of a wet clutch subjected to repeated engagement cycles. Pica et al. [16] provided a temperature and slip speed dependent model to investigate the torque characteristics of dry dual clutches. Gong et al. [17] investigated the wear behaviors of $\mathrm{Cu}$-based friction wet clutches by ring-on-ring test, and the dominant wear mechanisms were discussed. Hoic et al. [18] investigated the wear behaviors of dry dual clutch by experimental characterization and mathematical model. However, the investigations presented above mainly focused on the friction and wear behaviors of wet clutch friction pairs under normal operating conditions, and few of them investigated the friction and wear behaviors of $\mathrm{Cu}$-based friction pairs in wet clutches under severe operating conditions, especially the high temperature friction and wear behaviors.

In this paper, based on the $\mathrm{Cu}$-based wet multidisc clutches used in tracked-vehicle integrated transmissions, as shown in Figure 1, pin-on-disc tests are conducted on the UMT-3 to investigate the friction and wear behaviors of $\mathrm{Cu}-$ based friction pairs under severe operating conditions, especially the high temperature friction and wear behaviors. The friction coefficient and wear factor under different operating conditions and the high temperature wear mechanisms are primarily analyzed.

\section{Experimental Details}

The friction and wear behaviors of $\mathrm{Cu}$-based friction pairs in wet clutches crucially depend on the operating conditions.

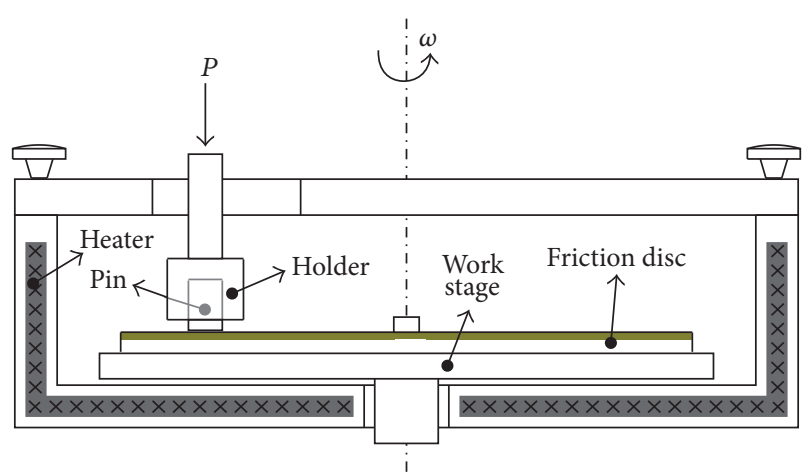

FIgURE 2: Elevated temperature chamber for rotary drives.

However, the local temperature, the local contact pressure, and the local relative sliding velocity are not constant on the contact surfaces of the friction pairs. Therefore, to better study the local friction and wear behaviors of $\mathrm{Cu}$-based friction pairs under different operating conditions, pin-on-disc tests are conducted on a professional test apparatus, Universal Material Tester (UMT), the model of which used in this paper is UMT-3, provided by the Bruker Corporation in the United States. Generally, during the engagement of wet clutches, a large quantity of heat is generated intensively in 1 second, and the lubricant film can fail due to the rapid temperature rise. Therefore, in this paper, the high temperature friction and wear behaviors of $\mathrm{Cu}$-based friction pairs are investigated by dry pin-on-disc tests, and there is no lubricant present during these experiments.

The structure of elevated temperature chamber for rotary drives is shown in Figure 2. The heating range of the elevated temperature chamber is $0 \sim 1000^{\circ} \mathrm{C}$. The diameter of the steel pin is $d=6 \mathrm{~mm}$, and the rotation radius of the sliding track on the friction disc is $r=25 \mathrm{~mm}$. In the process of testing, the pin was fixed with the sensor module, and the friction disc rotated with the rotary chamber.

The steel pin was made of $65 \mathrm{Mn}$ steel, and the friction disc was made of $\mathrm{Cu}$-based powder metallurgy material. Copper was the matrix material, and the iron powder ( $5 \%$ in weight), feldspar powder ( $5 \%$ in weight), carbon ( $6 \%$ in weight), and so forth were the additive materials. The RMS surface roughness of the friction disc was $0.61 \mu \mathrm{m}$. When the friction coefficient was stable after running in, we started the tests. When the temperature stabilized at the target temperature, we carried out the test procedures: (1) pressure the pin against the friction disc; (2) bring the electromotor to the target rotation speed; (3) record the rotation speed, load, temperature, and friction coefficient; (4) stop the electromotor and separate the pin and friction disc; (5) change the pin and disc with brand new ones. Operating parameter settings in pin-on-disc tests and corresponding values in wet clutches are shown in Table 1.

\section{Results and Discussion}

In order to investigate the high temperature friction and wear behaviors of $\mathrm{Cu}$-based friction pairs, the test results presented below are carried out with five different temperature levels, 
TABLE 1: Parameter settings in pin-on-disc tests and corresponding values in wet clutches.

\begin{tabular}{lc}
\hline Parameters & Values \\
\hline Rotation speed in pin-on-disc tests $(\mathrm{rpm})$ & $400,500,600,700,800$ \\
Relative sliding velocity in wet clutches $(\mathrm{mm} / \mathrm{s})$ & $1047,1309,1571,1833,2095$ \\
\hline Load in pin-on-disc tests $(\mathrm{N})$ & $60,80,100,120,140$ \\
Average surface pressure in wet clutches $(\mathrm{MPa})$ & $2.1,2.8,3.5,4.2,4.9$ \\
\hline Temperature in pin-on-disc tests $\left({ }^{\circ} \mathrm{C}\right)$ & $120,195,270,345,420$ \\
Temperature in wet clutches $\left({ }^{\circ} \mathrm{C}\right)$ & $120,195,270,345,420$ \\
\hline
\end{tabular}

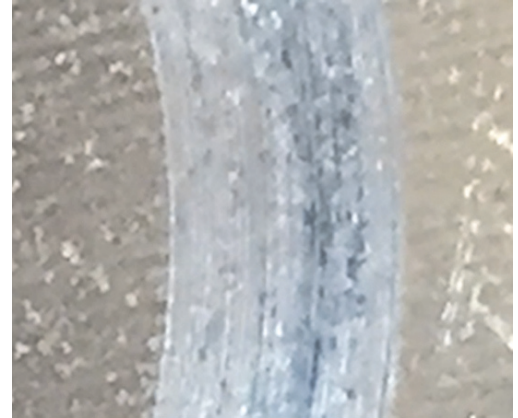

(a) $\mathrm{T}=120^{\circ} \mathrm{C}$

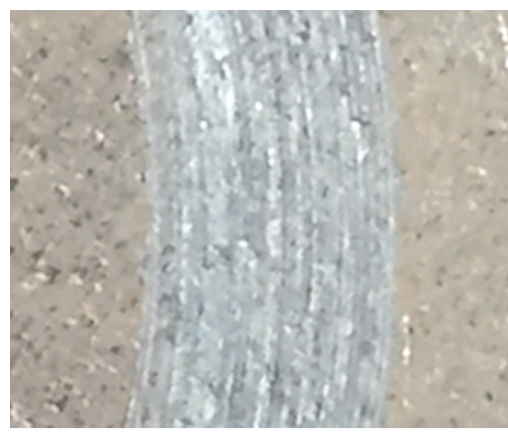

(b) $\mathrm{T}=195^{\circ} \mathrm{C}$

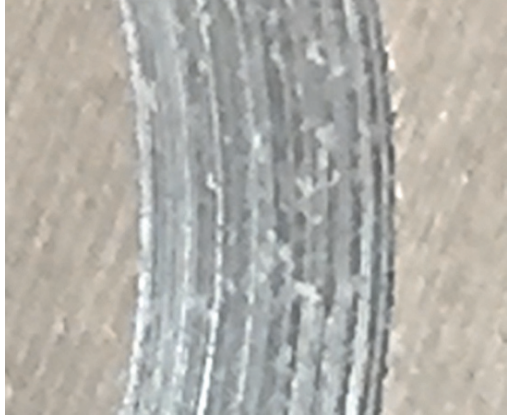

(c) $\mathrm{T}=270^{\circ} \mathrm{C}$

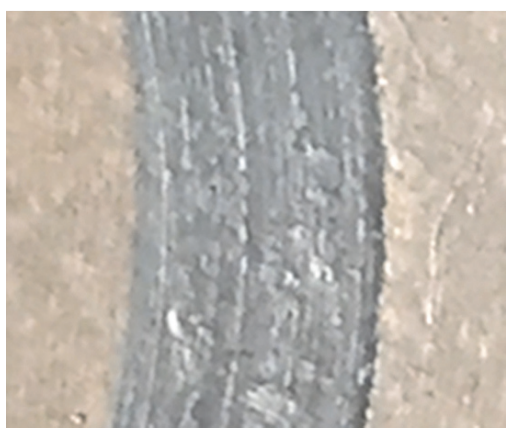

(d) $\mathrm{T}=345^{\circ} \mathrm{C}$

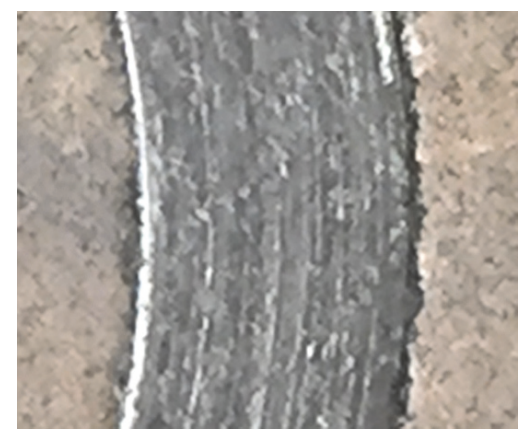

(e) $\mathrm{T}=420^{\circ} \mathrm{C}$

Figure 3: Friction discs after tests with different levels of temperature.

five different rotation speeds, and five different load levels. The test duration is 30 minutes. The friction coefficient, wear factor, and high temperature wear mechanism will be primarily analyzed in this part. The pin and the disc used in each experiment are brand new.

Figures 3(a)-3(e) show the surface state of the friction discs after tests with different temperatures. It is clear that the depth of wear groove increases significantly as the temperature rises. Furthermore, the friction condition and the wear mechanism of $\mathrm{Cu}$-based friction pairs change in the process of temperature rising.

Figure 4(a) presents the test results of friction coefficient and average friction coefficient under different temperatures. It is clear that temperature rise has a significant influence on the friction coefficient of $\mathrm{Cu}$-based friction pairs. When the temperature is $T=120^{\circ} \mathrm{C}$, the friction coefficient is stable and the mean value of friction coefficient is about 0.28 . As the temperature rises to $T=195^{\circ} \mathrm{C}$, the friction coefficient has slight fluctuation and the mean value increases to about 0.32 .
With the temperature $T=270^{\circ} \mathrm{C}$, the friction coefficient is the biggest, about 0.35 , and begins to vibrate obviously. Then, as the temperature rises to $T=345^{\circ} \mathrm{C}$, the friction coefficient deceases to about 0.33 and fluctuates strongly. When the temperature rises to $T=420^{\circ} \mathrm{C}$, the vibration of friction coefficient is significantly identified, and the mean value of the friction coefficient decreases to about 0.30 .

Figures 4(b) and 4(c) present the test results of friction coefficient and average friction coefficient under different rotation speeds and different loads. We can see that the effects of rotation speed and load on the friction coefficient of $\mathrm{Cu}-$ based friction pairs are also obvious. As the rotation speed increases from $400 \mathrm{rpm}$ to $800 \mathrm{rpm}$, the average friction coefficient decreases gradually from about 0.38 to 0.32 , and the vibration of the friction coefficient decreases at the same time. Similarly, as the load increases from $60 \mathrm{~N}$ to $140 \mathrm{~N}$, the average friction coefficient decreases gradually from about 0.39 to 0.32 , and there is no significant change in the vibration of the friction coefficient. 

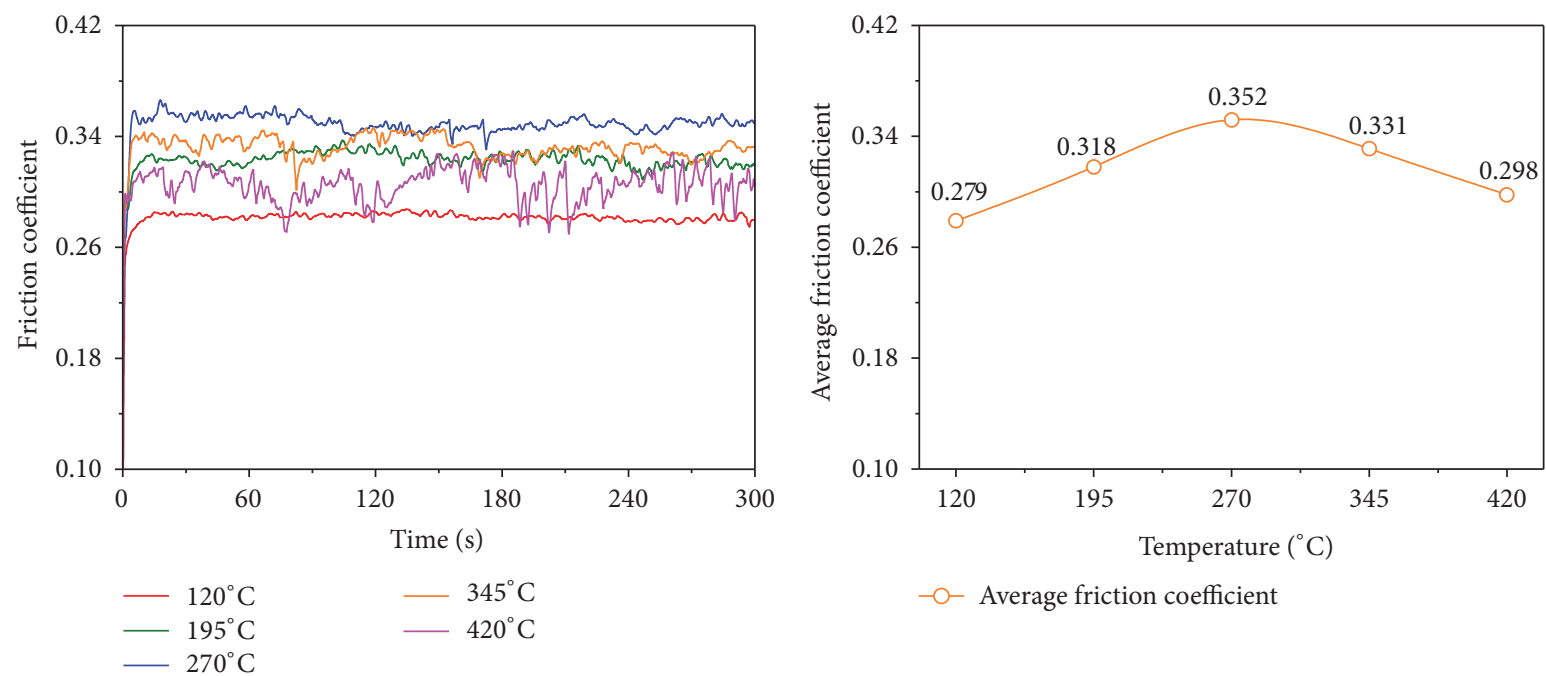

(a) Test results of friction coefficient under different temperatures
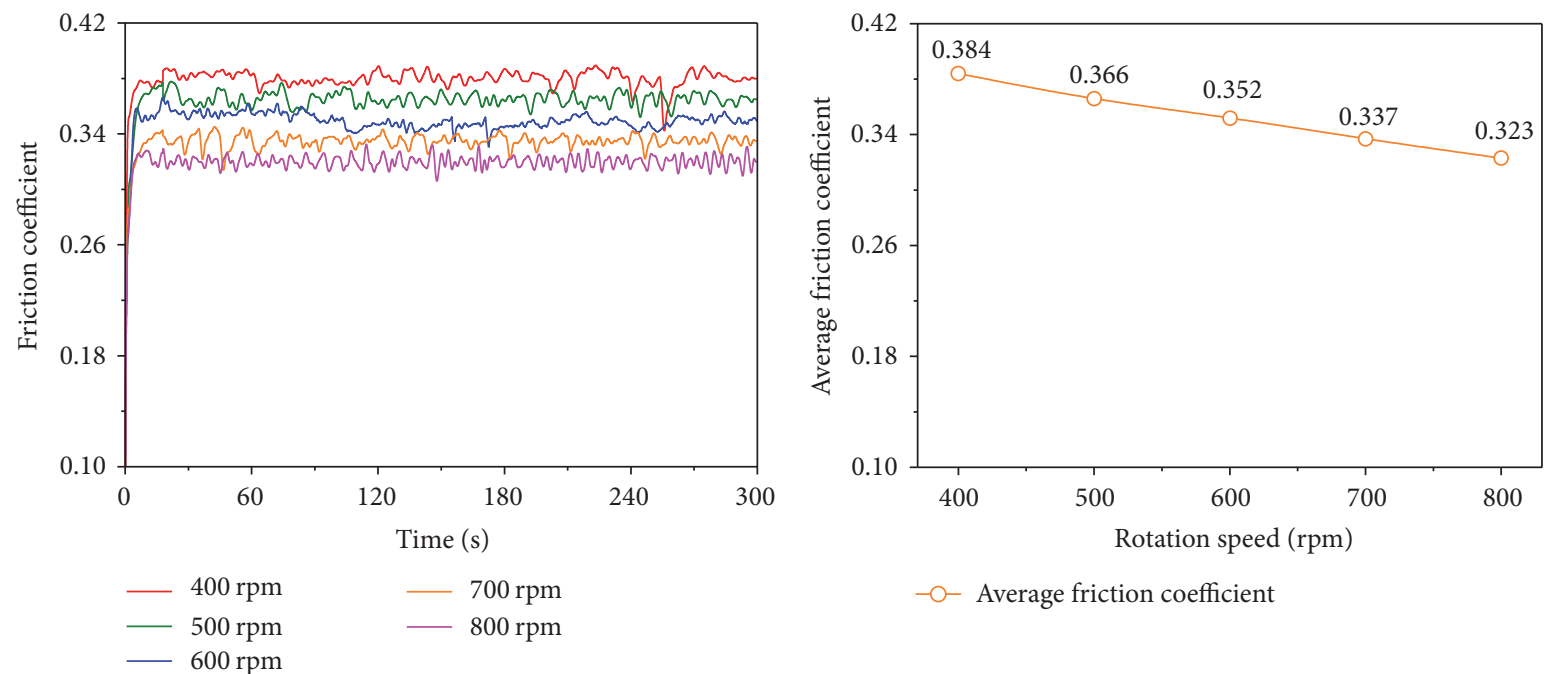

(b) Test results of friction coefficient under different rotation speeds
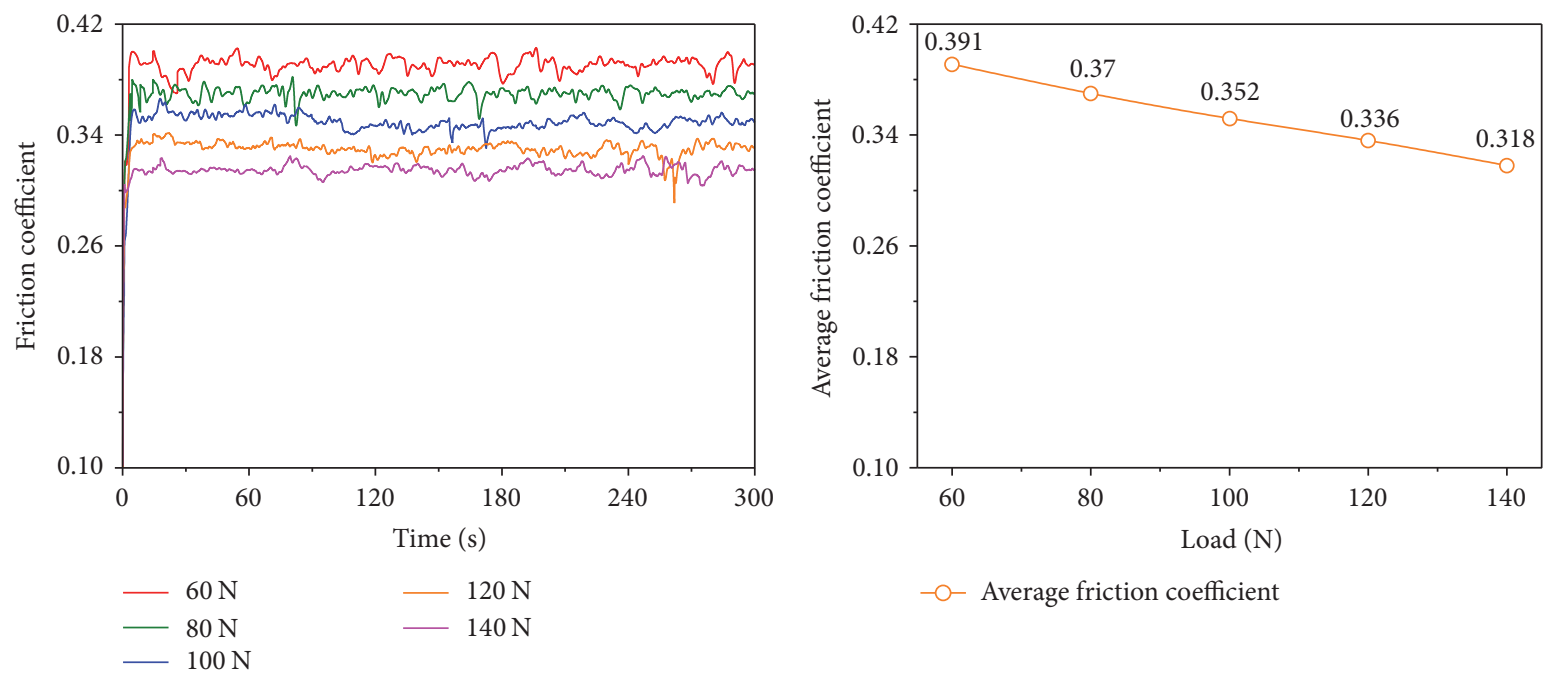

(c) Test results of friction coefficient under different loads

FIGURE 4: Test results of friction coefficient under different temperatures, rotation speeds, and loads. 


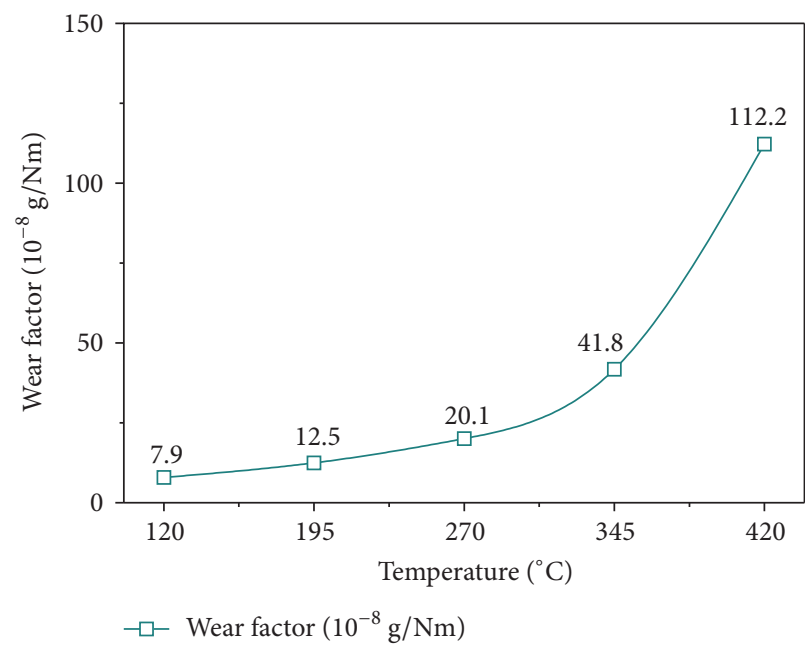

(a) Test results of wear factor under different temperatures

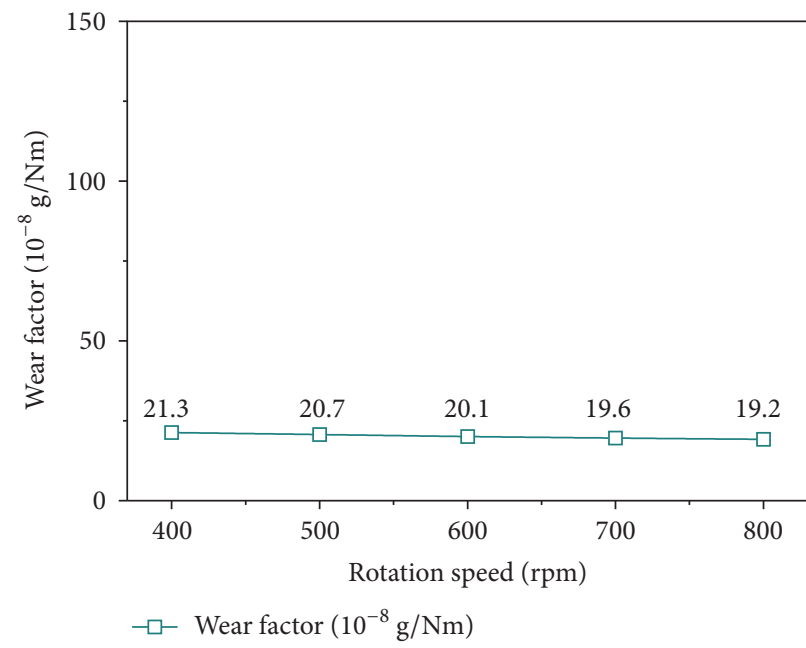

(b) Test results of wear factor under different rotation speeds

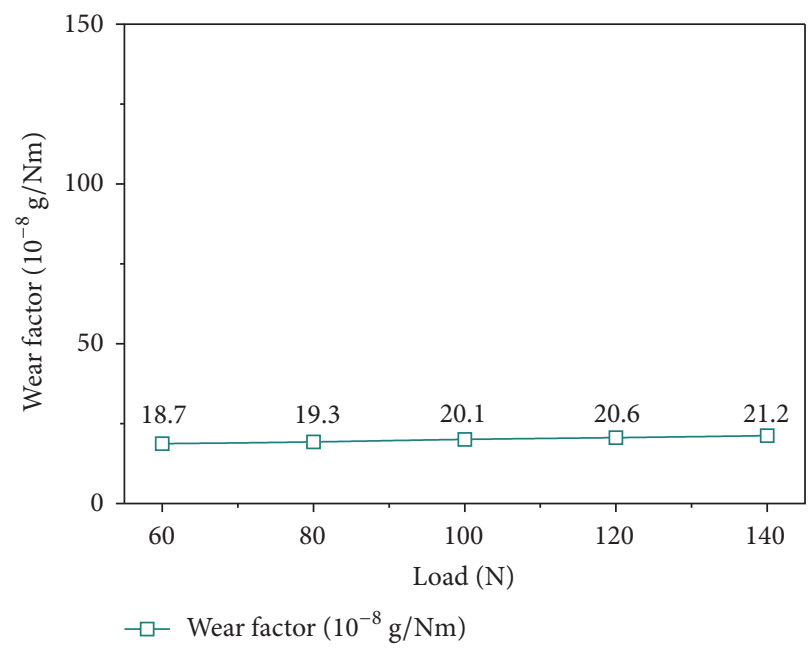

(c) Test results of wear factor under different loads

FIGURE 5: Test results of wear factor under different temperatures, rotation speeds, and loads.

The wear loss of the friction disc is measured by an electronic balance, and the wear factor can be calculated from the test result of weight loss by Archard's wear model:

$$
K=\frac{W_{\text {test }}}{F_{\text {test }} S},
$$

where $W_{\text {test }}$ is the test result of weight loss $(\mathrm{g}) ; F_{\text {test }}$ is the load of pin-on-disc test $(\mathrm{N})$; and $S$ is the total relative sliding distance of the pin and the disc (m). The unit of the wear factor $K$ is $\mathrm{g} / \mathrm{Nm}$.

Figure 5(a) shows the test results of wear factor under different temperatures. We can see that the wear of $\mathrm{Cu}$-based friction pairs seriously deteriorates when the temperature exceeds $345^{\circ} \mathrm{C}$. When the temperature is $T=120^{\circ} \mathrm{C}$, the wear of $\mathrm{Cu}$-based friction pairs is slight, and the wear factor is about $K=7.9 \times 10^{-8} \mathrm{~g} / \mathrm{Nm}$. As the temperature rises to $T=270^{\circ} \mathrm{C}$, the wear factor of $\mathrm{Cu}$-based friction pairs grows gradually to about $K=20.1 \times 10^{-8} \mathrm{~g} / \mathrm{Nm}$. When the temperature is higher than $T=300^{\circ} \mathrm{C}$, the growth of the wear factor becomes faster. When the temperature is $T=345^{\circ} \mathrm{C}$, the wear factor of $\mathrm{Cu}$-based friction pairs grows significantly to about $K=41.8 \times 10^{-8} \mathrm{~g} / \mathrm{Nm}$. However, as the temperature rises to $T=420^{\circ} \mathrm{C}$, the wear factor of $\mathrm{Cu}$-based friction pairs grows sharply to about $K=112.2 \times 10^{-8} \mathrm{~g} / \mathrm{Nm}$.

Figures 5(b) and 5(c) show the test results of wear factor under different rotation speeds and loads. We can see that there is no significant change in the wear factor of Cu-based friction pairs when the rotation speed or the load increases. As the rotation speed increases from $400 \mathrm{rpm}$ to $800 \mathrm{rpm}$, the wear factor decreases slightly from about $K=21.3 \times$ $10^{-8} \mathrm{~g} / \mathrm{Nm}$ to $K=19.2 \times 10^{-8} \mathrm{~g} / \mathrm{Nm}$. On the contrary, as the load increases from $60 \mathrm{~N}$ to $140 \mathrm{~N}$, the wear factor of the $\mathrm{Cu}$-based friction pairs increases slightly from about $K=$ $18.7 \times 10^{-8} \mathrm{~g} / \mathrm{Nm}$ to $K=21.2 \times 10^{-8} \mathrm{~g} / \mathrm{Nm}$.

Figures 6(a)-6(e) provide the SEM micrographs of worn surfaces of $\mathrm{Cu}$-based friction pairs after test under different temperatures. It is observed that the wear mechanism changes obviously as the temperature rises from $T=120^{\circ} \mathrm{C}$ to $T=$ $420^{\circ} \mathrm{C}$. When the temperature is $T=120^{\circ} \mathrm{C}$, the wear of the friction surface is slight, and the wear mechanism is abrasive 

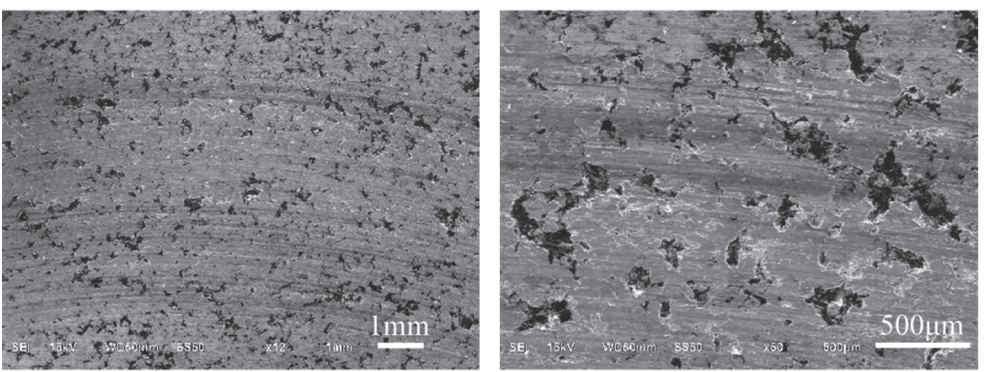

(a) $\mathrm{T}=120^{\circ} \mathrm{C}$
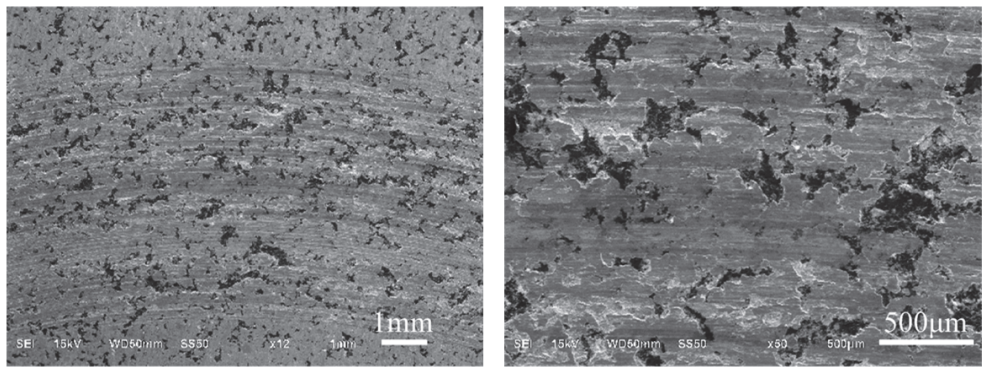

(b) $\mathrm{T}=195^{\circ} \mathrm{C}$
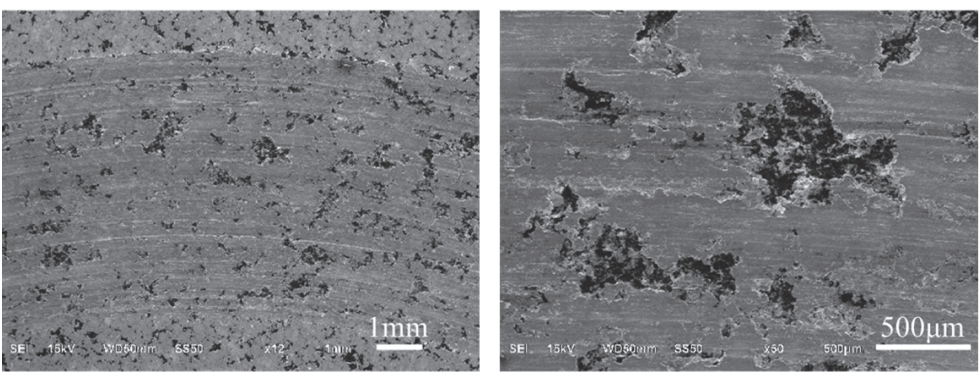

(c) $\mathrm{T}=270^{\circ} \mathrm{C}$
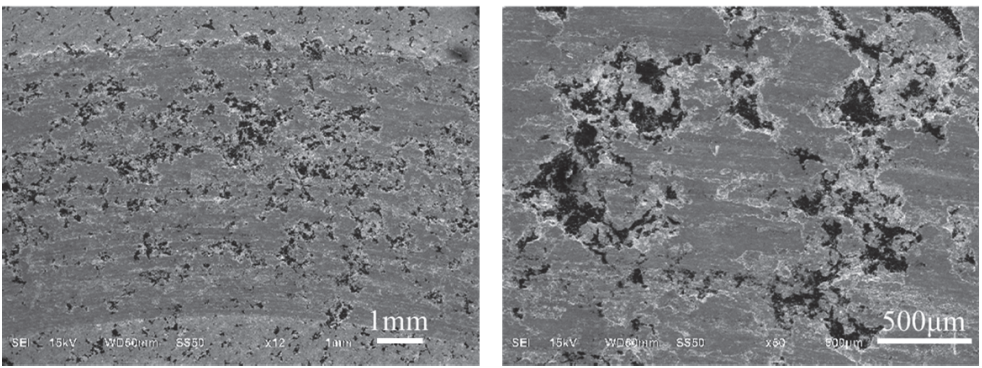

(d) $\mathrm{T}=345^{\circ} \mathrm{C}$
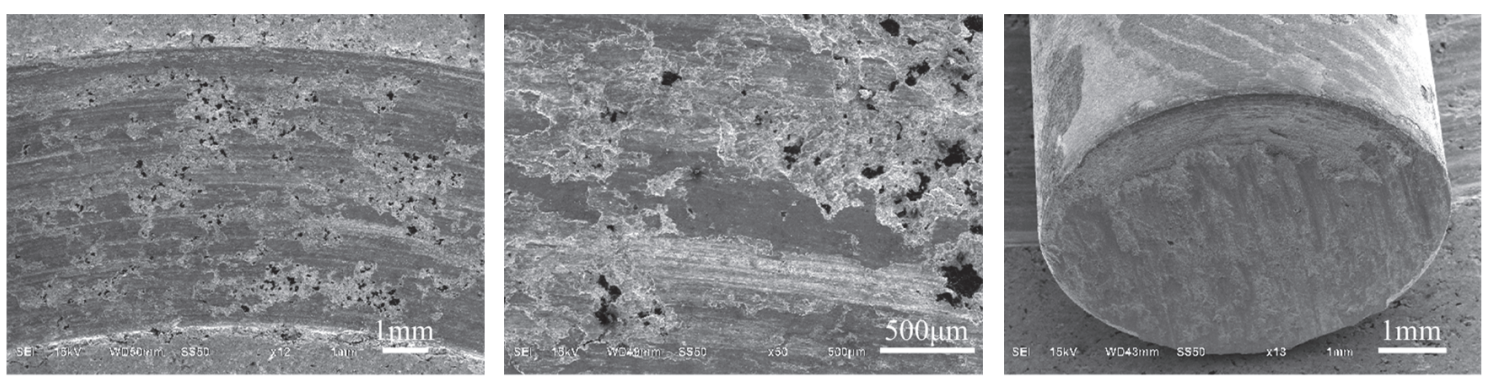

(e) $\mathrm{T}=420^{\circ} \mathrm{C}$
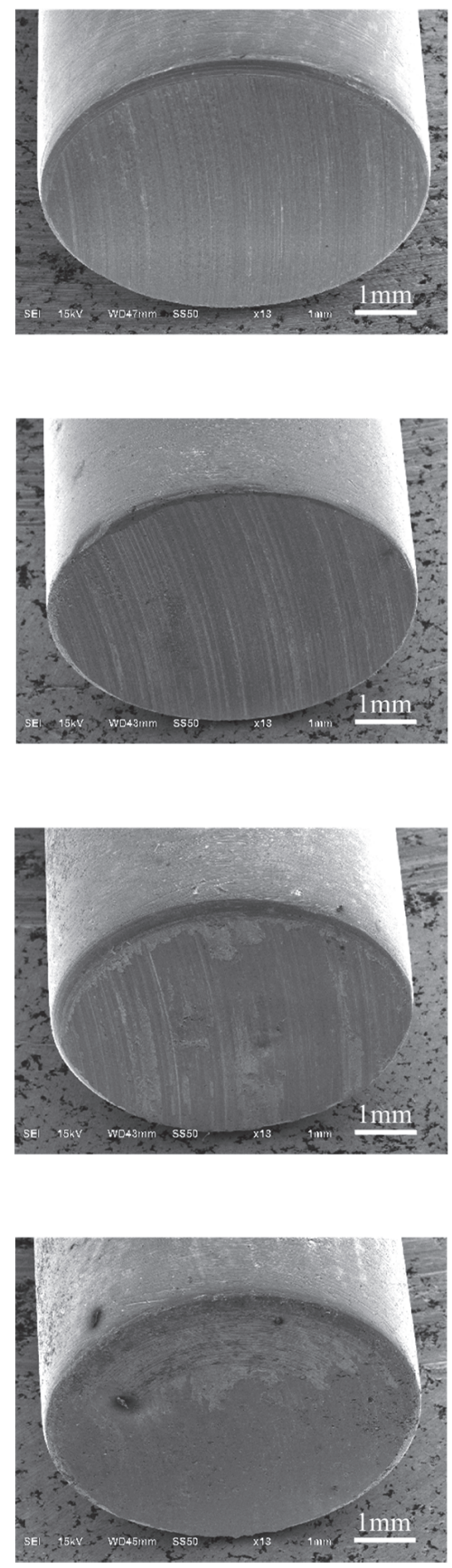

FIGURE 6: SEM micrographs of worn surfaces of $\mathrm{Cu}$-based friction pairs after the test. 
wear. As the temperature rises to $T=195^{\circ} \mathrm{C}$, the wear of the friction surface becomes more obvious, and the wear mechanism is still abrasive wear. When the temperature rises to $T=270^{\circ} \mathrm{C}$, some furrows emerge, and the wear mechanism becomes ploughing wear. As the temperature rises to $T=$ $345^{\circ} \mathrm{C}$, the $\mathrm{Cu}$-based powder metallurgy material begins to soften, and the main wear mechanism changes to adhesive wear. When the temperature rises continuously to extremely high $T=420^{\circ} \mathrm{C}$, the wear of $\mathrm{Cu}$-based friction pairs deteriorates seriously, and there are massive exfoliations on the friction surface, when the wear mechanism changes to delamination wear.

\section{Conclusions}

The high temperature friction and wear behaviors of $\mathrm{Cu}$ based friction pairs in wet clutches have been investigated based on pin-on-disc tests. The friction coefficient, wear factor, and high temperature wear mechanism have been primarily analyzed. The main conclusions are summarized as follows:

(1) When the temperature is $120^{\circ} \mathrm{C}$, the friction coefficient of $\mathrm{Cu}$-based friction pairs is stable. As the temperature rises to $420^{\circ} \mathrm{C}$, the friction coefficient begins to vibrate significantly. The friction coefficient increases from 0.28 to 0.35 when the temperature rises from $120^{\circ} \mathrm{C}$ to $270^{\circ} \mathrm{C}$ and decreases to 0.30 when the temperature continuously rises to $420^{\circ} \mathrm{C}$.

(2) When the temperature rises from $120^{\circ} \mathrm{C}$ to $270^{\circ} \mathrm{C}$, the wear of $\mathrm{Cu}$-based friction pairs is slight, and the wear factor grows gradually from $K=7.9 \times 10^{-8} \mathrm{~g} / \mathrm{Nm}$ to $K=20.1 \times 10^{-8} \mathrm{~g} / \mathrm{Nm}$. However, as the temperature rises from $345^{\circ} \mathrm{C}$ to $420^{\circ} \mathrm{C}$, the wear factor grows sharply from $K=41.8 \times 10^{-8} \mathrm{~g} / \mathrm{Nm}$ to $K=112.2 \times$ $10^{-8} \mathrm{~g} / \mathrm{Nm}$.

(3) When the temperature is lower than $345^{\circ} \mathrm{C}$, the main wear mechanisms are abrasive wear and ploughing wear. As the temperature rises to higher than $345^{\circ} \mathrm{C}$, the wear of $\mathrm{Cu}$-based friction pairs seriously deteriorates, and the wear mechanism changes to adhesive wear and delamination wear.

\section{Conflicts of Interest}

The authors declare that they have no conflicts of interest regarding the publication of this paper.

\section{Acknowledgments}

The authors would like to express their appreciation for the continuous support from Professor Wen-zhong Wang at Beijing Institute of Technology. Furthermore, the authors acknowledge the financial support from the National Natural Science Foundation of China (no. 51575042).

\section{References}

[1] H. Gao, G. C. Barber, and M. Shillor, "Numerical simulation of engagement of a wet clutch with skewed surface roughness," Journal of Tribology, vol. 124, no. 2, pp. 305-312, 2002.

[2] J. Deur, J. Petric, J. Asgari, and D. Hrovat, "Modeling of wet clutch engagement including a thorough experimental validation," SAE Technical Papers, 2005.

[3] A. P. Ompusunggu, P. Sas, and H. Van Brussel, "Modeling and simulation of the engagement dynamics of a wet friction clutch system subjected to degradation: An application to condition monitoring and prognostics," Mechatronics, vol. 23, no. 6, pp. 700-712, 2013.

[4] S. Iqbal, F. Al-Bender, A. P. Ompusunggu, B. Pluymers, and W. Desmet, "Modeling and analysis of wet friction clutch engagement dynamics," Mechanical Systems and Signal Processing, vol. 60-61, pp. 420-436, 2015.

[5] M. Mansouri, M. Holgerson, M. M. Khonsari, and W. Aung, "Thermal and dynamic characterization of wet clutch engagement with provision for drive Torque," Journal of Tribology, vol. 123, no. 2, pp. 313-323, 2001.

[6] T.-C. Jen and D. J. Nemecek, "Thermal analysis of a wet-disk clutch subjected to a constant energy engagement," International Journal of Heat and Mass Transfer, vol. 51, no. 7-8, pp. 1757-1769, 2008.

[7] M. Ingram, T. Reddyhoff, and H. A. Spikes, "Thermal behaviour of a slipping wet clutch contact," Tribology Letters, vol. 41, no. 1, pp. 23-32, 2011.

[8] H. Seo, C. Zheng, W. Lim, S. W. Cha, and S. Han, "Temperature prediction model of wet clutch in coupling," in Proceedings of the 7th IEEE Vehicle Power and Propulsion Conference, VPPC 2011, pp. 1-4, IEEE, Chicago, IL, USA, September 2011.

[9] L. Wenbin, H. Jianfeng, F. Jie, C. Liyun, and Y. Chunyan, "Simulation and application of temperature field of carbon fabric wet clutch during engagement based on finite element analysis," International Communications in Heat and Mass Transfer, vol. 71, pp. 180-187, 2016.

[10] X. Xiong, J. Chen, P. Yao, S. Li, and B. Huang, "Friction and wear behaviors and mechanisms of $\mathrm{Fe}$ and $\mathrm{SiO}_{2}$ in $\mathrm{Cu}$-based P/M friction materials," Wear, vol. 262, no. 9-10, pp. 1182-1186, 2007.

[11] W. Ost, P. De Baets, and J. Degrieck, "The tribological behaviour of paper friction plates for wet clutch application investigated on SAE\#II and pin-on-disk test rigs," Wear, vol. 249, no. 5-6, pp. 361-371, 2001.

[12] P. Nyman, R. Mäki, R. Olsson, and B. Ganemi, "Influence of surface topography on friction characteristics in wet clutch applications," Wear, vol. 261, no. 1, pp. 46-52, 2006.

[13] P.-P. Yao, H.-C. Sheng, X. Xiong, and B.-Y. Huang, "Worn surface characteristics of $\mathrm{Cu}$-based powder metallurgy bake materials for aircraft," Transactions of Nonferrous Metals Society of China, vol. 17, no. 1, pp. 99-103, 2007.

[14] X. Zhou, P. Walker, N. Zhang, B. Zhu, and J. Ruan, "Numerical and experimental investigation of drag torque in a two-speed dual clutch transmission," Mechanism and Machine Theory, vol. 79, pp. 46-63, 2014.

[15] M. Li, M. M. Khonsari, D. M. C. McCarthy, and J. Lundin, "On the wear prediction of the paper-based friction materialin a wet clutch," Wear, vol. 334-335, pp. 56-66, 2015.

[16] G. Pica, C. Cervone, A. Senatore, M. Lupo, and F. Vasca, "Dry dual clutch torque model with temperature and slip speed 
effects," Intelligent Industrial Systems, vol. 2, no. 2, pp. 133-147, 2016.

[17] T. Gong, P. Yao, Y. Xiao et al., "Wear map for a copper-based friction clutch material under oil lubrication," Wear, vol. 328329, pp. 270-276, 2015.

[18] M. Hoic, N. Kranjcevic, Z. Herold, J. Deur, and V. Ivanovic, "Experimental characterization and modeling of dry dual clutch wear," SAE International Journal of Passenger Cars-Mechanical Systems, vol. 7, no. 1, pp. 326-337, 2014. 

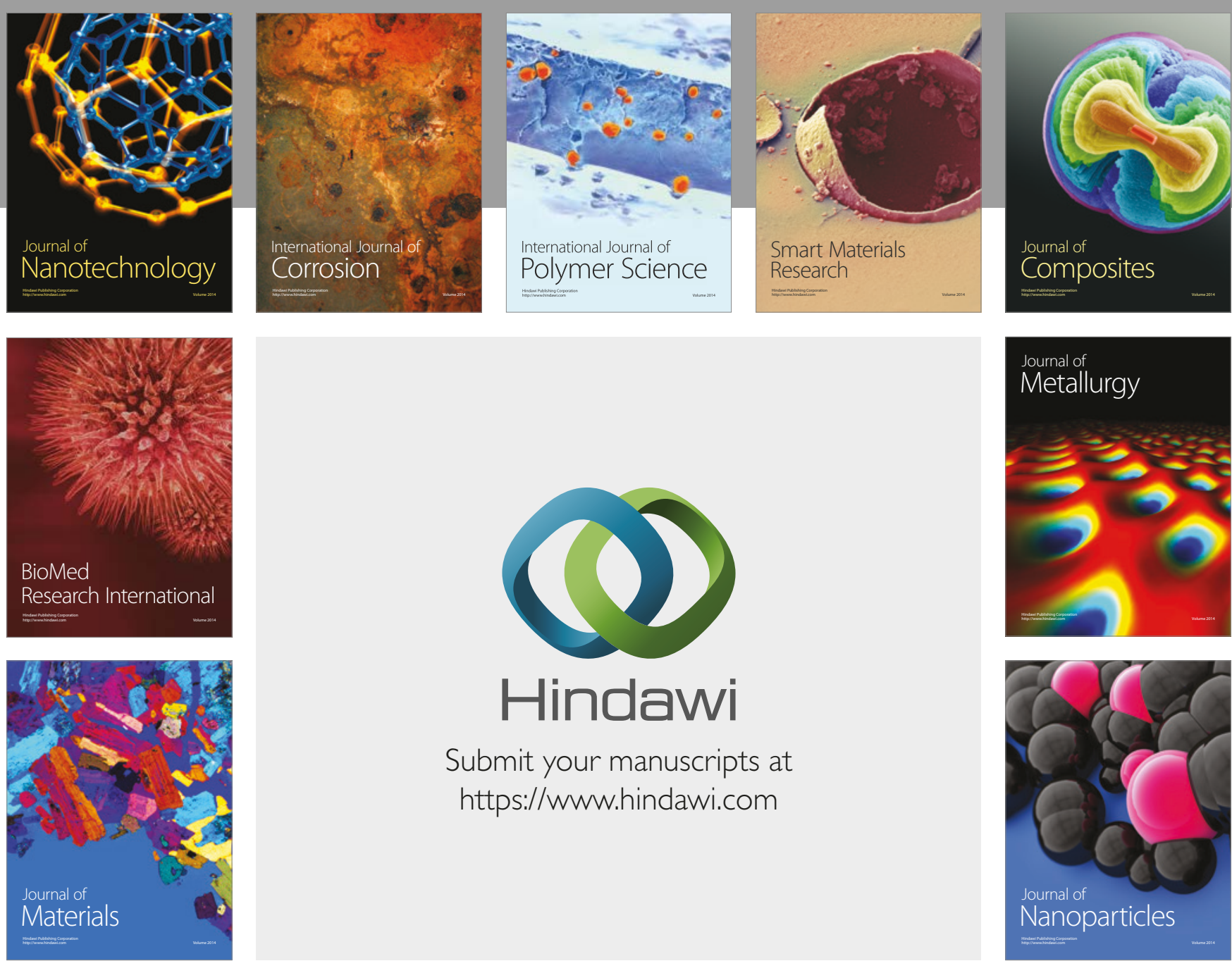

\section{Hindawi}

Submit your manuscripts at

https://www.hindawi.com
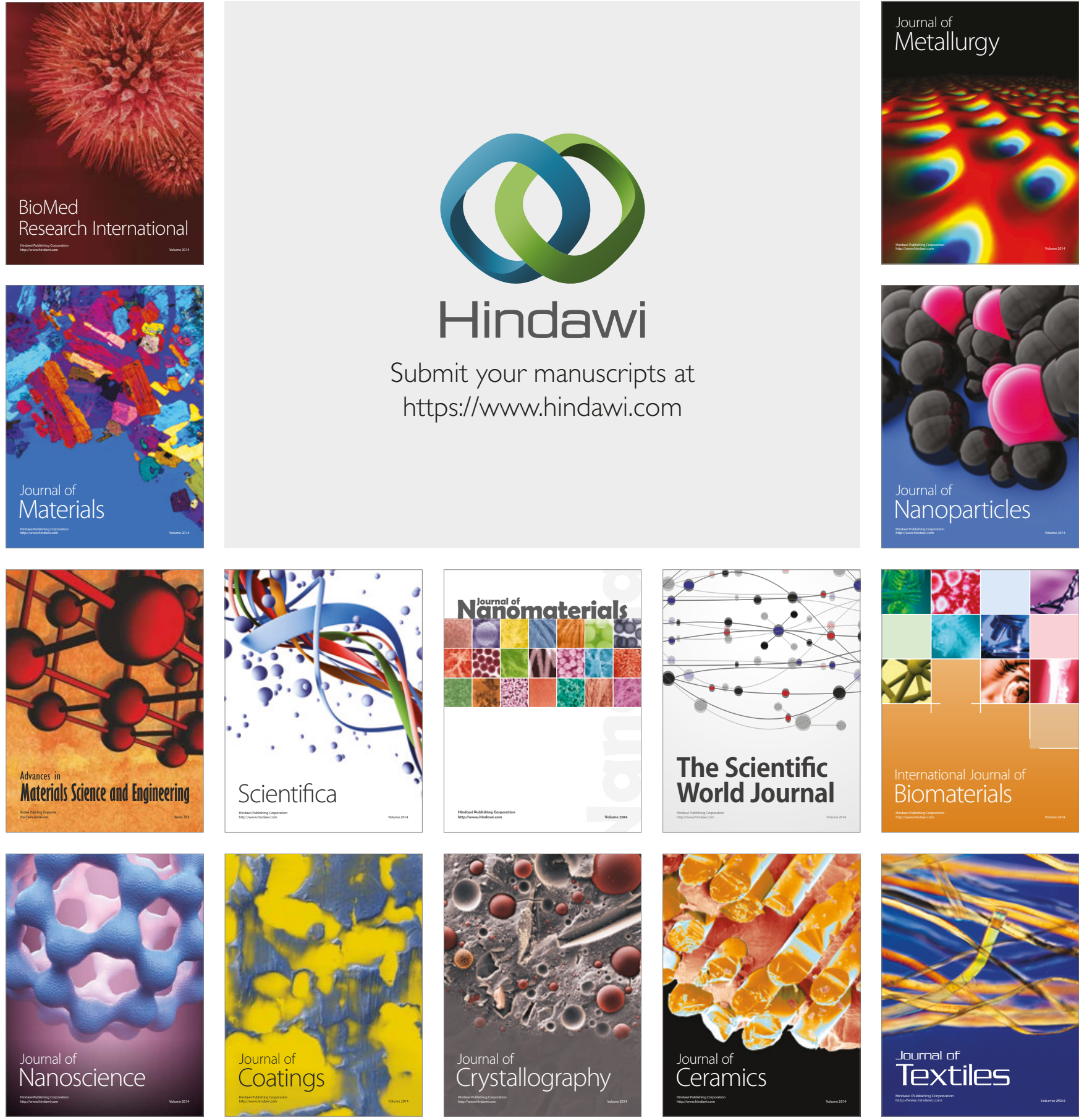

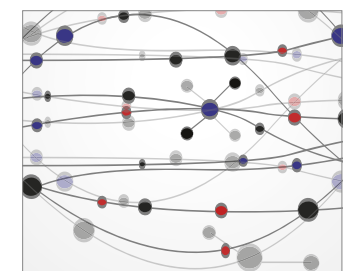

The Scientific World Journal
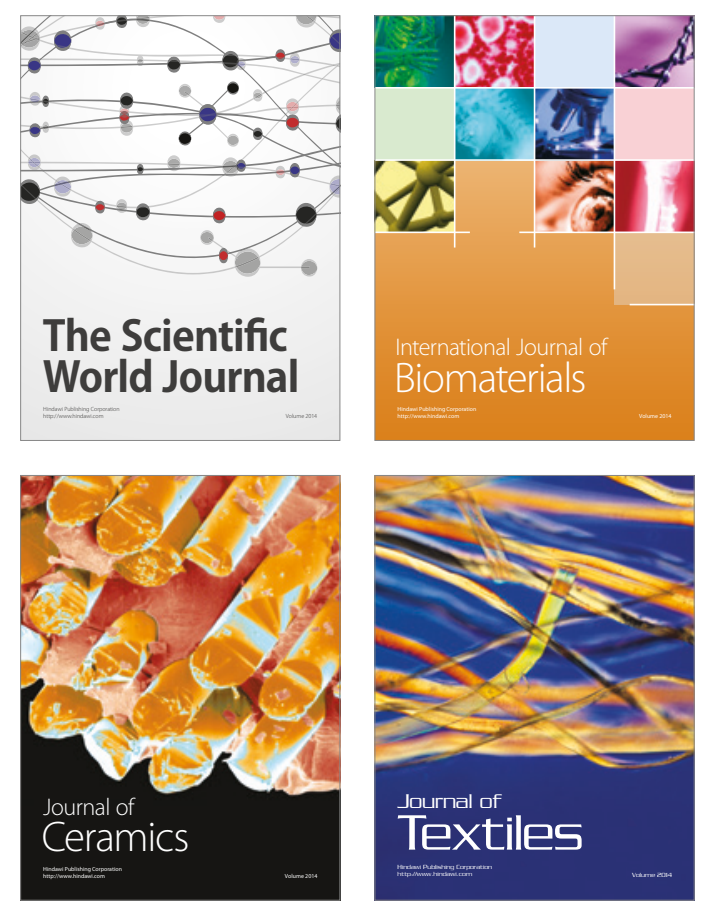